\title{
Sialylation transmogrifies human breast and pancreatic cancer cells into 3D multicellular tumor spheroids using cyclic RGD- peptide induced self-assembly
}

\author{
Roman Akasov ${ }^{\text {, Sabah Haq }}$, Fiona Haxho², Vanessa Samuel${ }^{2}$, Sergey V. Burov ${ }^{3}$, \\ Elena Markvicheva ${ }^{1}$, Ronald J. Neufeld ${ }^{4}$, Myron R. Szewczuk ${ }^{2}$ \\ ${ }^{1}$ Shemyakin-Ovchinnikov Institute of Bioorganic Chemistry, Russian Academy of Sciences, 117997 Moscow, Russia \\ ${ }^{2}$ Department of Biomedical and Molecular Sciences, Queen's University, Kingston, Ontario, K7L 3N6 Canada \\ ${ }^{3}$ Institute of Macromolecular Compounds, Russian Academy of Sciences, Petersburg, 119004 Russia \\ ${ }^{4}$ Department of Chemical Engineering, Queen's University, Kingston, Ontario, K7L 3N6 Canada \\ Correspondence to: Elena Markvicheva, email: lemarkv@hotmail.com \\ Ronald J. Neufeld, email: neufeld@queensu.ca \\ Myron R. Szewczuk, email: szewczuk@queensu.ca \\ Keywords: sialylation, spheroids, oseltamivir phosphate, pancreatic cancer, breast cancer \\ Received: June 21, $2016 \quad$ Accepted: August 25, $2016 \quad$ Published: September 06, 2016
}

\section{ABSTRACT}

Multicellular tumor spheroids (MTS) have been at the forefront of cancer research, designed to mimic tumor-like developmental patterns in vitro. Tumor growth in vivo is highly influenced by aberrant cell surface-specific sialoglycan structures on glycoproteins. Aberrant sialoglycan patterns that facilitate MTS formation are not well defined. Matrix-free spheroids from breast MCF-7 and pancreatic PANC1 cancer cell lines and their respective tamoxifen (TMX) and gemcitabine (Gem) resistant variants were generated using the RGD platform of cyclic Arg-Gly-Asp-D-Phe-Lys peptide modified with 4-carboxybutyl-triphenylphosphonium bromide (cyclo-RGDfK (TPP)). MCF-7 and MCF-7 TMX cells formed tight spheroids both in the classical agaroseand RGD-based platforms while all PANC1 cells formed loose aggregates. Using lectin histochemistry staining, sialidase assay, neuraminidase (Vibrio cholerae) and oseltamivir phosphate (OP) neuraminidase inhibitor treatments, MCF-7 and PANC1 cells and their drug-resistant variants expressed different sialic acid (SA) content on their cell surfaces. $\alpha-2,3-$ and $\alpha-2,6$-sialic acid surface residues facilitated spheroid formation under cyclo-RGDfK(TPP)-induced self-assembly. Pretreatment with $\alpha-2,3-$ SA specific Maackia amurensis (MAL-II) lectin, $\alpha-2,6-S A$ specific Sambucus nigra (SNA) lectin, and exogenous $\alpha-2,6-S A$ specific neuraminidase (Vibrio cholerae) dosedependently reduced spheroid volume. OP enhanced cell aggregation and compaction forming spheroids. PANC1 and MDA-MB231 xenograft tumors from untreated and OP-treated RAGXC $\gamma$ double mutant mice expressed significantly higher levels of $\alpha-2,3-$ SA over $\alpha-2,6-S A$. MCF-7 spheroids also expressed a high $\alpha-2,3-S A$ to $\alpha-2,6-S A$ ratio. These results suggest that the relative levels of specific sialoglycan structures on the cell surface correlate with the ability of cancer cells to form avascular multicellular tumor spheroids and in vivo xenograft tumors.

\section{INTRODUCTION}

The multicellular tumor spheroid (MTS) is a promising 3D model platform that enables the study of tumor cell development, morphology, cellular motility and drug resistance in vitro [1-4]. The MTS mimics the in vivo microenvironment which plays a dominant role in multidrug resistance and various cell processes, including epithelial-mesenchymal transition (EMT) and metastasis $[5,6]$. MTSs are generally used for novel anticancer drug screening $[7,8]$. Since spheroids resemble the 3D architecture of avascular tumors, including multicellular 
arrangement and extracellular matrix deposition typically found in vivo, spheroid cells also demonstrate enhanced resistance to chemotherapy [9]. Tumor spheroids in matrigel or in ECM-based matrixes are good study models to investigate cell motility and anti-metastatic compounds in vitro [6, 10]. However, novel MTS formations, particularly under matrix-free conditions, are being developed to study the 3D architecture of avascular tumor models $[1,9,11-13]$, especially in relation to metastasis, invasion and therapeutic drug screening [13, 14]. Presently, the molecular development of MTS formation by cancer cells may involve (a) cell surface proteins binding fibronectin which induces 3D cohesion [15], (b) under conditions of random positioning machine (RPM) simulating microgravity, the expression of 28 genes aside from $\beta$-tubulin is mutually controlled by a key cytokine interleukin-8 (IL-8 or CXCL8) gene within the framework of 6 extracellular, 6 membrane, 15 cytoplasmic and 2 nuclear proteins [16], and/or (c) the integrins' interactions with the extracellular matrices (ECM) and intracellular components within the cellular cytoskeleton in particular response to mechanical stimulation $[16,17]$.

It has been reported that MTS formation involves a number of highly glycosylated integrins such as $\alpha v \beta 3$ and $\alpha 5 \beta 1$ on the cell surface $[18,19]$. It is well known that integrin expression correlates with metastases in a large variety of cancers [20]. Since integrins are highly glycosylated receptors, recent reports have reviewed altered expression of sialylated glycoproteins with elevated levels of cell-surface $\alpha 2,6$-sialic acids (SA) that are linked to colorectal cancer metastasis, radioresistance, and chemoresistance $[21,22]$. In addition, the altered mammalian sialidase(s) expression was reported not to result from metastatic potential, but rather from a determining event affecting metastatic ability [23]. It was proposed by the report that SA expression on tumor cell surfaces appears to vary from cell to cell. Other reports have shown that altered sialylation of glycoproteins is closely associated with metastatic potential and cell invasiveness [24-29]. With regard to integrins, Pocheć et al. [30] proposed that the $\beta 1-6$-branched sialic acid of $\alpha v \beta 3$ integrins promotes the metastatic characteristics and migration of melanoma cells.

Recently, we have shown that a synthetic cyclic RGD-peptide induces formation of 3D MTS in a simple, single-step, reproducible procedure. The resulting MTS can be developed and employed as 3D models for assessing antitumor drug efficacy [31] and was studied in twelve cancer cell lines. The report describes the selfassembly of cancer cells from monolayer cultures into MTS, a process that was directly induced by the RGDpeptide. The self-assembly formation of monolayer cultures into MTS was induced by the cyclic Arg-GlyAsp-D-Phe-Lys (cyclo-RGDfK) peptide, modified with 4-carboxybutyl-triphenylphosphonium bromide cation (TPP). The resulting modified peptide, cyclo-
RGDfK(TPP) was used in the concentration range of 10-100 uM. The 3D characterization of the spheroids showed unimodal structures, ranging from 60-120 $\mu \mathrm{m}$ in diameter, and varying between cell lines and medium serum concentration [31]. The report also proposes that these cyclo-RGDfK(TPP) peptides mimick the natural ECM protein's ability to induce cell aggregation via $\alpha 5 \beta 1$ integrin.

To evaluate the role of sialylation of cancer cell surfaces in spheroid formation, we used the cycloRGDfK(TPP) approach to biochemically induce cell aggregation and compaction, transmogrifying monolayer cancer cells into tumor spheroids.

\section{RESULTS}

\section{Spheroid formation}

The ability of cancer cells and their chemoresistant variants to form spheroids was studied using the RGDpeptide-based platform which causes specific biochemical alterations of cell surface receptors. These alterations induced self-assembly in monolayer cell cultures into 3D MTS by facilitating cell-cell recognitions, interactions and adhesion [31]. The hypothesis is that the RGD-peptide platform potentiates a higher tendency for cell clustering and compaction. To test this hypothesis, we asked whether the RGD-peptide approach is a universal platform to form tumor spheroids. Here, human breast adenocarcinoma MCF-7 cells formed tight compact spheroids using both the classical and RGD-based platforms (Figures 1A and 1C), while pancreatic carcinoma PANC1 cells formed only loose aggregates even after 7 days of incubation (Figure 1B and 1D). PANC1 cells forming aggregatelike spheroids are consistent with another report using PANC1 cells on tissue culture dishes containing conditioned serum-free medium [32]. We have reported similar aggregate-like irregular spheroids using cycloRGDfK(TPP) for malignant melanoma A-375 cells [31].

The ability of MCF-7 and PANC1 cells to form spheroids is proposed here to be dependent on the property of the cell lines, and not on the platform used. Using the cyclo-RGDfK(TPP) peptide approach to form spheroids, tamoxifen-resistant MCF-7 TMX (Figure 1B) and gemcitabine-resistant PANC1-GemR (Figure 1D) cells readily formed spheroids compared with their parental cell lines. The MCF-7 TMX cells formed complete spheroids after 7 days of incubation with $25 \mu \mathrm{M}$ cycloRGDfK(TPP), while parental MCF-7 cells did not form clear-cut spheroids under these conditions (Figure 1C). To generate spheroids from MCF-7 cells, a minimum of 50 $\mu \mathrm{M}$ cyclo-RGDfK(TPP) was needed. For PANC1-GemR cells, the formation of irregular spheroid-like aggregates was observed after 3-4 days of incubation with $12.5 \mu \mathrm{M}$ of cyclo-RGDfK(TPP) (Figure 1D), while $25 \mu \mathrm{M}$ peptide was required for parental PANC1. In contrast, cells on 


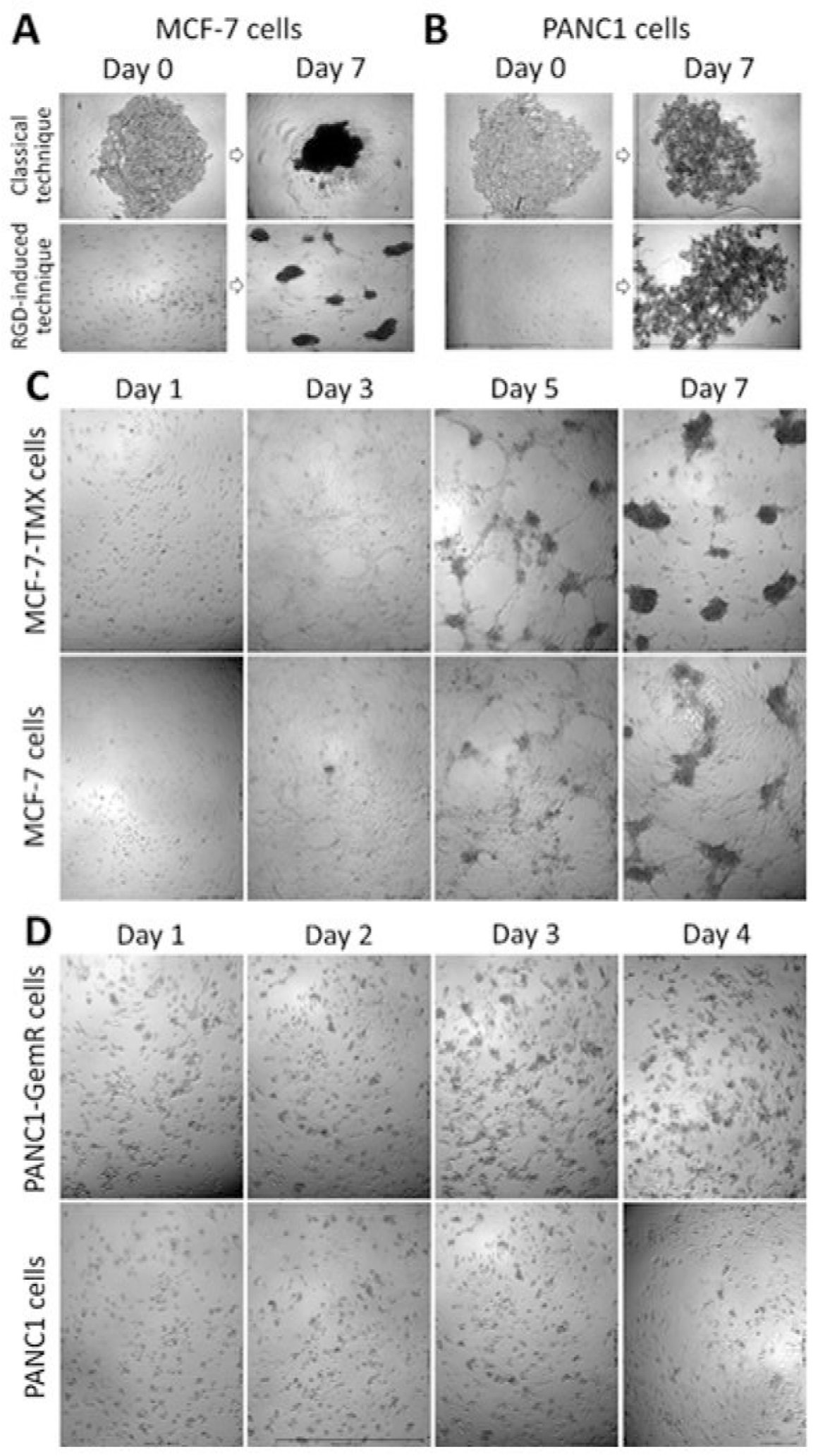

Figure 1: Phase-contrast images of time-dependent spheroid-forming cells derived from MCF-7 A, C. and PANC1 B, D.; 4x objective. (A) and (B) spheroid forming cell aggregation on agarose-coated surfaces vs RGD-induced platform using 10,000 cells per well of 96-well plate for 7 days of incubation. The cyclo-RGDfK(TPP) concentration was $25 \mu \mathrm{M}$ for PANC1 cells and $50 \mu \mathrm{M}$ for MCF-7 cells. (C) MCF-7 vs MCF-7 TMX and (D) PANC1 vs PANC1-GemR spheroid-forming cell aggregation in the presence of $25 \mu \mathrm{M}$ (C) and 12.5 $\mu \mathrm{M}$ (D) cyclo-RGDfK(TPP) with 10,000 cells per well, 1-7 days of incubation. 
agarose-coated plates did not show any differences in spheroid cell formation between MCF-7 and MCF-7 TMX cells (Supplemental Figure 1). Collectively, the results suggest that the chemoresistant cancer cells may have characteristic properties that make them more liable to cell aggregation and compaction using the cyclo-RGDfK(TPP) platform compared with the parental cell lines.

Using the cyclo-RGDfK(TPP) peptide platform, we determined the optimal ability of cell aggregation and compaction, leading to the formation of spheroids. Here, the growth of MCF-7, MCF-7-TMX, PANC1 and PANC1-GemR spheroid cells was facilitated by cycloRGDfK(TPP) peptide at different concentrations, and performed the cell proliferation assay using the WST-1 reagent [33]. The reagent was added simultaneously to the removed supernatant with floating spheroids and to the residual monolayer cells adherent to the well plate after 4 days of cell growth. Live cell numbers are proportional to absorbance at $420 \mathrm{~nm}$. For MCF-7 TMX cells, more floating spheroid cells and less adherent cells were found compared to MCF-7 cells in the range of $12.5-50 \mu \mathrm{M}$
cyclo-RGDfK(TPP) (Figure 2). There were no differences found up to $6.25 \mu \mathrm{M}$ of cyclo-RGDfK(TPP) peptide (no spheroid formation) and for $100 \mu \mathrm{M}$ of peptide (spheroid cells). Collectively, cyclo-RGDfK(TPP) peptide clearly promoted spheroid formation dose-dependently for both parental and chemoresistant cells. The effects of the peptide in promoting spheroid formation are more robust for the MCF-7 TMX cells than the MCF-7 cells over most of the range of peptide concentrations. The effect of cyclo-RGDfK(TPP) peptide on PANC1-GemR spheroid formation is better in the mid-range of $25 \mu \mathrm{M}$ of cycloRGDfK(TPP) peptide concentration, but the differences are not significant at low and high concentrations of peptide.

\section{Sialylation of cell surface glycoproteins in multicellular tumor spheroid formation}

Since MTS and CD24- and CD44-overexpressing cancer stem-like PANC1 cells show high expression of fucosylated glycans using specific lectins binding to
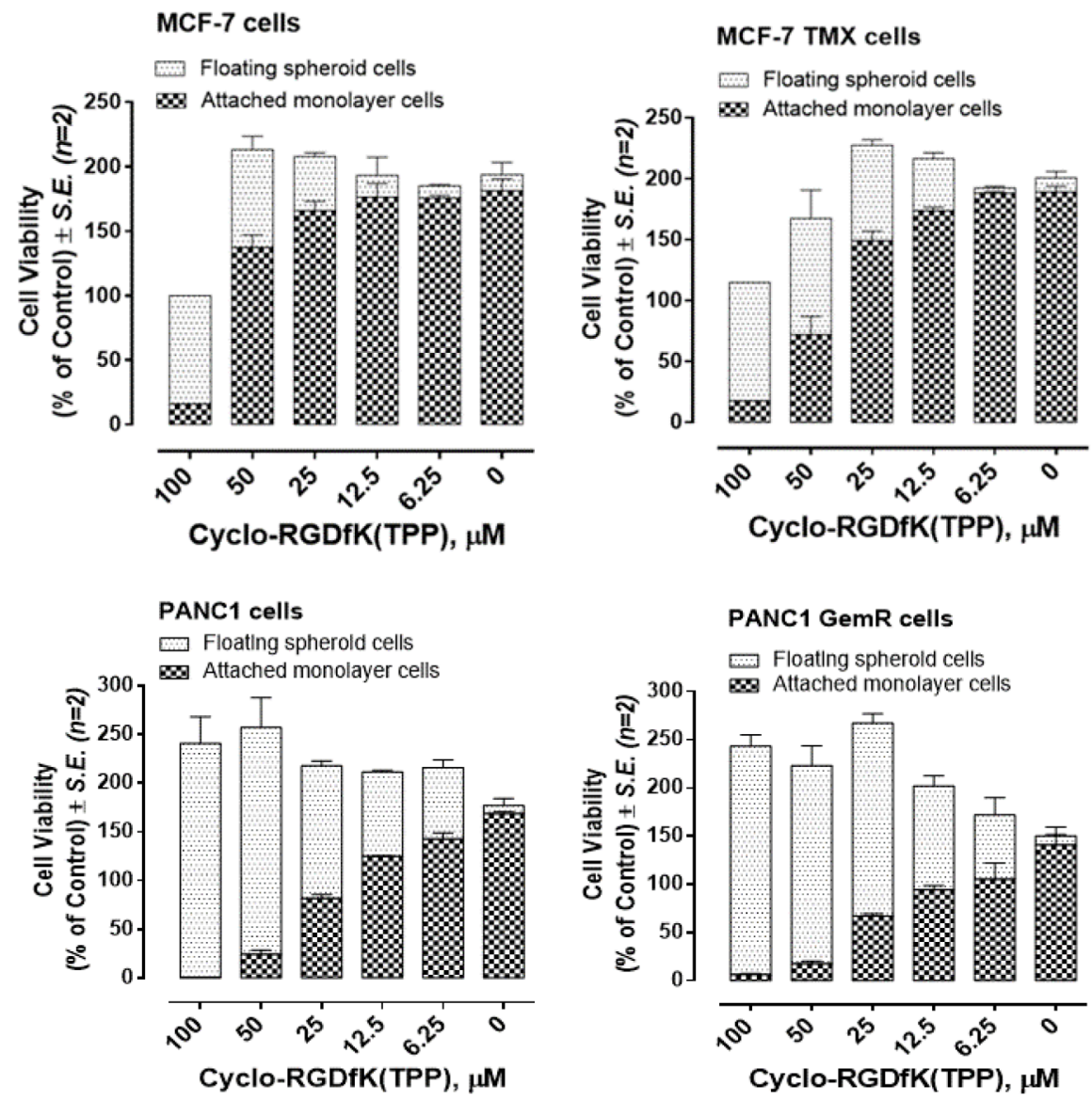

Figure 2: Cell viability of monolayer attached and spheroid-floating MCF-7, MCF-7 TMX, PANC1 and PANC1 GemR cells treated with cyclo-RGDfK(TPP) at indicated doses using modified WST-1 assay. Cells were incubated in 96-well plates $(5,000$ cells $/$ well $)$ and allowed to adhere for 24 hours in $1 \times$ DMEM containing $10 \%$ FCS. The media were replaced with fresh DMEM containing 5\% FCS with or without various concentrations of cyclo-RGDfK(TPP) for 4 days of incubation. Cell viability is expressed as cell viability ( $\%$ of control) \pm S.E. of two independent experiments. 
the spheroid cells [32], we examined prior to spheroid formation the cell surface sialylation of monolayer MCF7, MCF-7 TMX cells (Figure 3), and PANC1 and PANC1GemR cells (Figure 4). This analysis was conducted using lectin histochemistry staining and flow cytometry with $\alpha$-2,3-sialic acid (SA) specific Maackia amurensis (MALII) and $\alpha-2,6-$ SA specific Sambucus nigra (SNA). The data indicate that the chemoresistant MCF-7 TMX cells (Figure $3 \mathrm{G})$ have more $\alpha-2,3-\mathrm{SA}$ cell surface expression than $\alpha-2,6-\mathrm{SA}$ compared to the parental cell lines as determined by flow cytometry analyses. The significance of these findings suggest that chemoresistant MCF-7 TMX and PANC1-GemR may have particular sialylated N-linked glycans that contribute to the metastatic phenotype and potential of tumor cells, as proposed by Dennis and Laferte [25], Park and Lee [21] and Haxho et al. [22]. In support of our data, Cui et al. [34] examined the $\alpha 2,3-$ SA expression levels in primary and pair-matched lymph node metastatic human tumors as well in triple negative MDA-MB-231, invasive ductal breast carcinoma T-47D and MCF-7 cell lines. Their data showed that the primary lymph node metastatic tumors had significantly elevated levels of $\alpha 2,3-\mathrm{SA}$ compared to that of primary ones. In addition, the highly metastatic MBA-MB-231 breast cancer cell line also expressed the highest $\alpha 2,3-\mathrm{SA}$ content compared to other cell lines. These findings were shown to be linked to the $\alpha 2,3$ sialyltransferase mRNA levels.
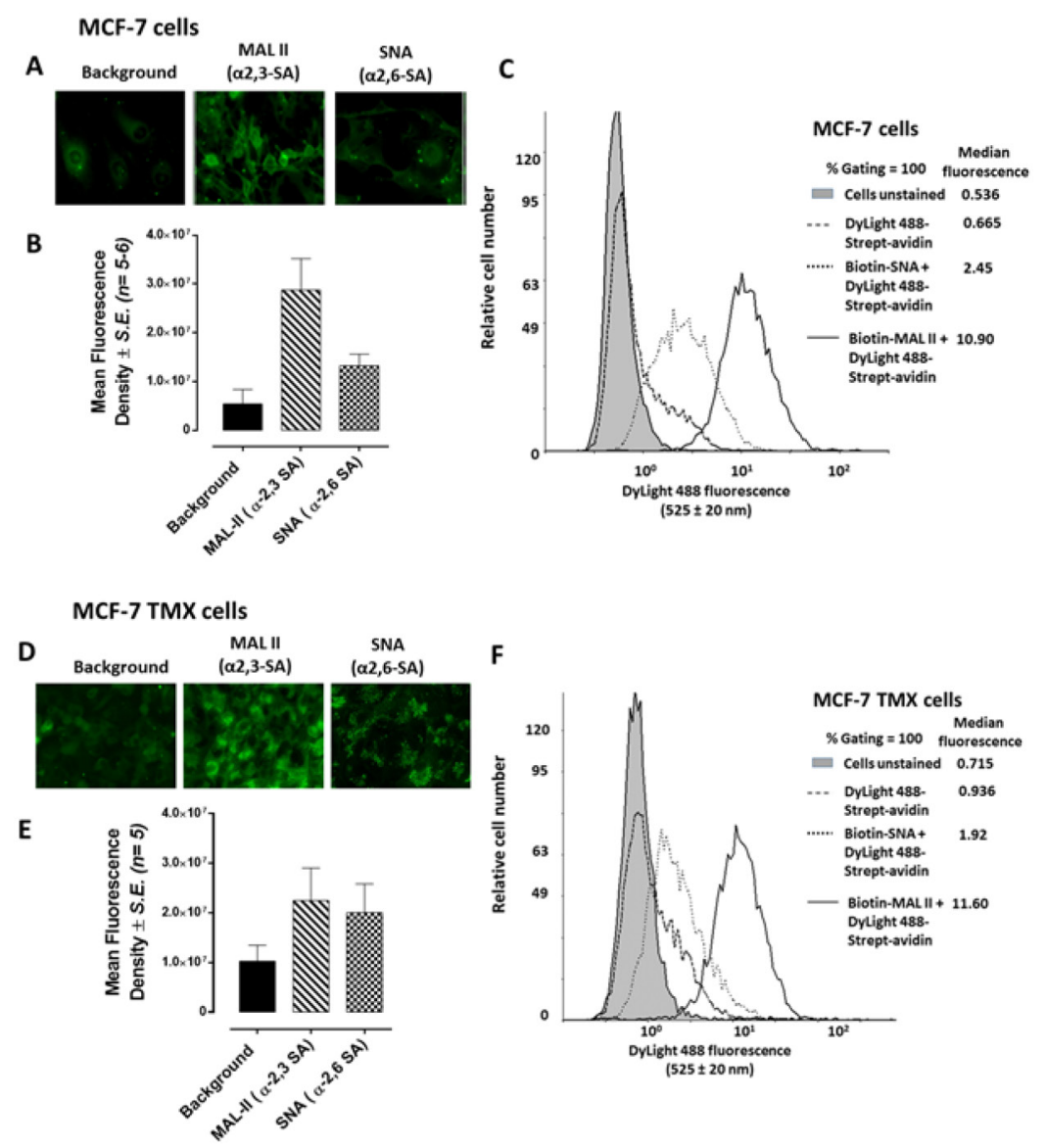

G

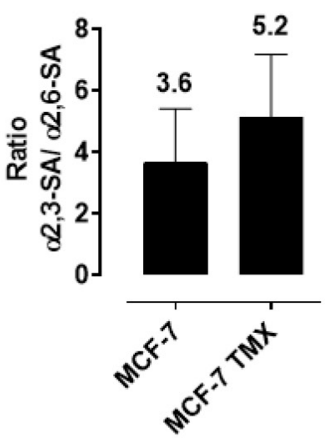

Figure 3: Fluorescent microscopy images of MCF-7 A. and MCF-7 TMX D. cells stained with biotinylated MAL-II and SNA on ice followed with avidin-fluorescein and fixed. Background has only the avidin-fluorescein. Stained cells were visualized by epifluorescence microscopy using a x20 objective. B. and E. Quantitative analysis was done by assessing the density of cell staining corrected for background for 5-6 separate image panels using Corel Photo Paint 8.0 software. Each bar in the graphs represents the mean fluorescence corrected density of staining $\pm S$.E. (error bars) for all cells within the respective images. C. and F. Flow cytometry analysis of biotinylated MAL II or biotinylated SNA staining of cell surface of live indicated cells. Histograms show staining with biotinylated lectins after incubation on ice for $1 \mathrm{hr}$ and followed with DyLight 488 conjugated streptavidin for additional $30 \mathrm{~min}$ on ice. Control cells were stained with DyLight 488 conjugated streptavidin for $30 \mathrm{~min}$ on ice. Cells were analyzed by Beckman Coulter Cytomics FC500 flow cytometry and CxP software (Beckman Coulter). Overlay histograms are displayed. Control unstained cells are depicted as gray-filled histogram; DyLight 488 conjugated streptavidin treated cells, black-dashed unfilled histogram; biotinylated SNA stained cells plus DyLight 488 conjugated streptavidin, dotted black line unfilled histogram; biotinylated MAL II stained cells plus DyLight 488 conjugated streptavidin, black line unfilled histogram. The median fluorescence for each histogram is for 500,000 acquired cells (100\% gated). G. Graph of normalized ratios of $\alpha 2,3-\mathrm{SA} / \alpha 2,6-\mathrm{SA}$ to the unstained cells from flow cytometry analyses is displayed. The data are the mean \pm S.E.M. of 2-3 independent experiments. 
Other reports have shown that the catalytic cleavage of SA of E-cadherin on the cell surface of MCF-7 cells by neuraminidase (from Vibrio cholerae, cleavage rate of $\alpha 2,6-\mathrm{SA}>\alpha 2,3-\mathrm{SA}>\alpha 2,8-\mathrm{SA})$ prevented cell adhesion or aggregation [35]. We hypothesized that the cell surface expression of $\alpha 2,6-\mathrm{SA}$ facilitates spheroid formation. Here, pretreatment of MCF-7 cells with a neuraminidase (from Vibrio cholerae) was performed followed with MALII and SNA lectin histochemistry staining. Treatment of MCF-7 cells with 25U of neuraminidase for $24 \mathrm{hrs}$ showed a pronounced removal of $\alpha 2,6$-SA compared with no effects on $\alpha 2,3-\mathrm{SA}$ (Figure $5 \mathrm{~A}$ ). The data in Figure $5 \mathrm{~B}$ clearly support the hypothesis. $\mathrm{MCF}-7$ cells treated with $0.25 \mathrm{U}$ or $25 \mathrm{U}$ neuraminidase in the presence of 50 $\mu \mathrm{M}$ cyclo-RGDfK(TPP) significantly reduced spheroid volume compared with the untreated control. To measure spheroid volume, we defined a spheroid as a compact rounded aggregation of cells with a distinct border of diameter $\geq 60 \mu \mathrm{m}$ containing cells indistinguishable from one another, according to Akasov et al. [31].

To test the role of SA on spheroid formation, we performed a lectin inhibition assay where monolayers of MCF-7 cells were treated with $M$. amurensis lectin MAL II ( $\alpha 2,3-\mathrm{SA})$, Sambucus nigra lectin SNA $(\alpha 2,6-$ $\mathrm{SA}$, peanut agglutinin (PNA, galactosyl ( $\beta-1,3)$ $\mathrm{N}$-acetylgalactosamine), or wheat germ agglutinin (WGA, $\mathrm{N}$-acetylglucosamine residues) in a dose-dependent manner together each with $50 \mu \mathrm{M}$ cyclo-RGDfK(TPP) for 4 days of incubation. Pretreatment of MCF-7 cells with MAL II and SNA lectins dose-dependently and significantly reduced spheroid formation in the presence of $50 \mu \mathrm{M}$ cyclo-RGDfK(TPP) (Figure 6A and 6B). In contrast, PNA and WGA had no inhibitory effects on cyclo-RGDfK(TPP)-induced MCF-7 spheroid formation (Figure 6C and 6D). It is noteworthy that WGA was shown to have an $\mathrm{IC}_{50}$ of $5.4 \mu \mathrm{g} / \mathrm{mL}$ for monolayer $\mathrm{MCF}$ 7 cells based on the cell viability assay (data not shown), which is consistent with another report [36].

We have recently shown activation of epidermal growth factor receptors (EGFR) is regulated by a cellsurface signaling complex involving neuraminidase-1 (Neu1), matrix metaloproteinase-9 (MMP9), and the neuromedin B G protein-coupled receptor (GPCR) [37]. The report also provided evidence to indicate that Neu1
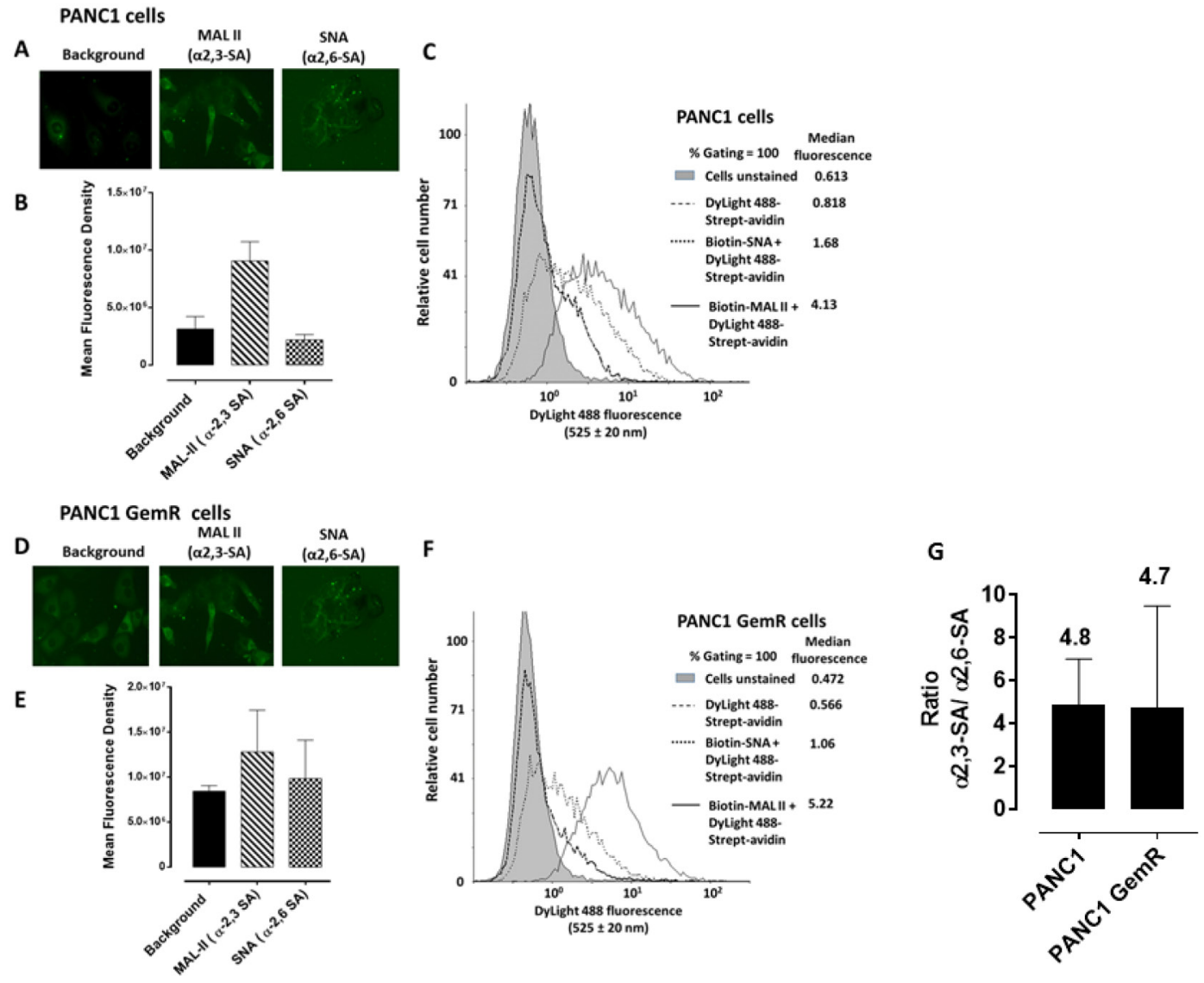

Figure 4: Fluorescent microscopy images of PANC1 A. and PANC1 GemR D. cells stained with biotinylated MAL-II and SNA on ice followed with avidin-fluorescein and fixed. Background control has only the avidin-fluorescein. Stained cells were visualized by epifluorescence microscopy using a x 20 objective. B, C, E, F, G. Quantitative analysis and flow cytometry analyses are similarly described in Figure 3 except for the flow data, where the median fluorescence for each histogram is indicated for 200000 acquired cells (100\% gated). 
specifically cleaves $\alpha-2,3-\mathrm{SA}$ on EGF receptors to remove steric hindrance of the receptor, with subsequent receptor association, activation and downstream signaling. Neu1 complexed with MMP-9 and GPCR tethered to receptor tyrosine kinases (RTKs) and TOLL-like receptors (TLRs) has been reported by us as a major target in multistage tumorigenesis [22]. Furthermore, Neu4 sialidase has been reported to be a regulator of neurospheres derived from patient samples and glioblastoma multiforme (GBM) cell line [38]. The report provided strong evidence to demonstrate that Neu4 overexpression is associated with an upregulation of stem cell-like properties in neuroblastoma cells. Remarkably, Neu4 expression levels were significantly decreased in differentiated and nonneurosphere GBM cells.

If activated Neu1 and Neu4 in complex with glycosylated receptors act as promoters of spheroid formation, it is important to assess the sialidase activity of live cells in both monolayer cultures, as well as MTS. In this report, we conducted a live cell sialidase assay [39-41] to determine whether the selected cancer cell lines express sialidase activity on their surface. Naïve live
MCF-7 and PANC1 cells exhibited significantly more sialidase activity than the chemoresistant variants, $\mathrm{MCF}-7$ TMX and PANC1-GemR (Figure 7A). Mean fluorescence surrounding viable cells is depicted in the bar graph (Figure 7B). Collectively, sialidase activity reduction on the surface of chemoresistant MCF-7 TMX and PANC1GemR cells identifies them as non-sphere-differentiated chemoresistant cells, similar to previous reports for nonneurosphere-differentiated GBM cells [38].

We have also reported that oseltamivir phosphate (OP) inhibits Neu1 [41] and Neu4 [42] sialidase activity with $\mathrm{IC}_{50}$ values of $1.175 \mu \mathrm{M}$ for LPS-stimulated BMC2 macrophage cells and $0.019 \mu \mathrm{M}$ for thymoquinone (TQ)-stimulated BMC2 cells, respectively. TQ specifically activates Neu4 sialidase [38, 42, 43]. Here, we used MCF-7, PANC1 and PANC1-GemR cells to determine if OP-inhibition of sialidase activity is involved in cyclo-RGDfK(TPP)facilitated spheroid formation. MCF-7 cells treated with OP $(400 \mu \mathrm{g} / \mathrm{mL})$ and cyclo-RGDfK(TPP) $(50 \mu \mathrm{M})$ produced early visible spheroids after 1-3 days and an increase in spheroid volume by day 5 (Figure $7 \mathrm{~B}$ and $7 \mathrm{C}$ ). There was a decrease in spheroid volume by day 7 in the presence of

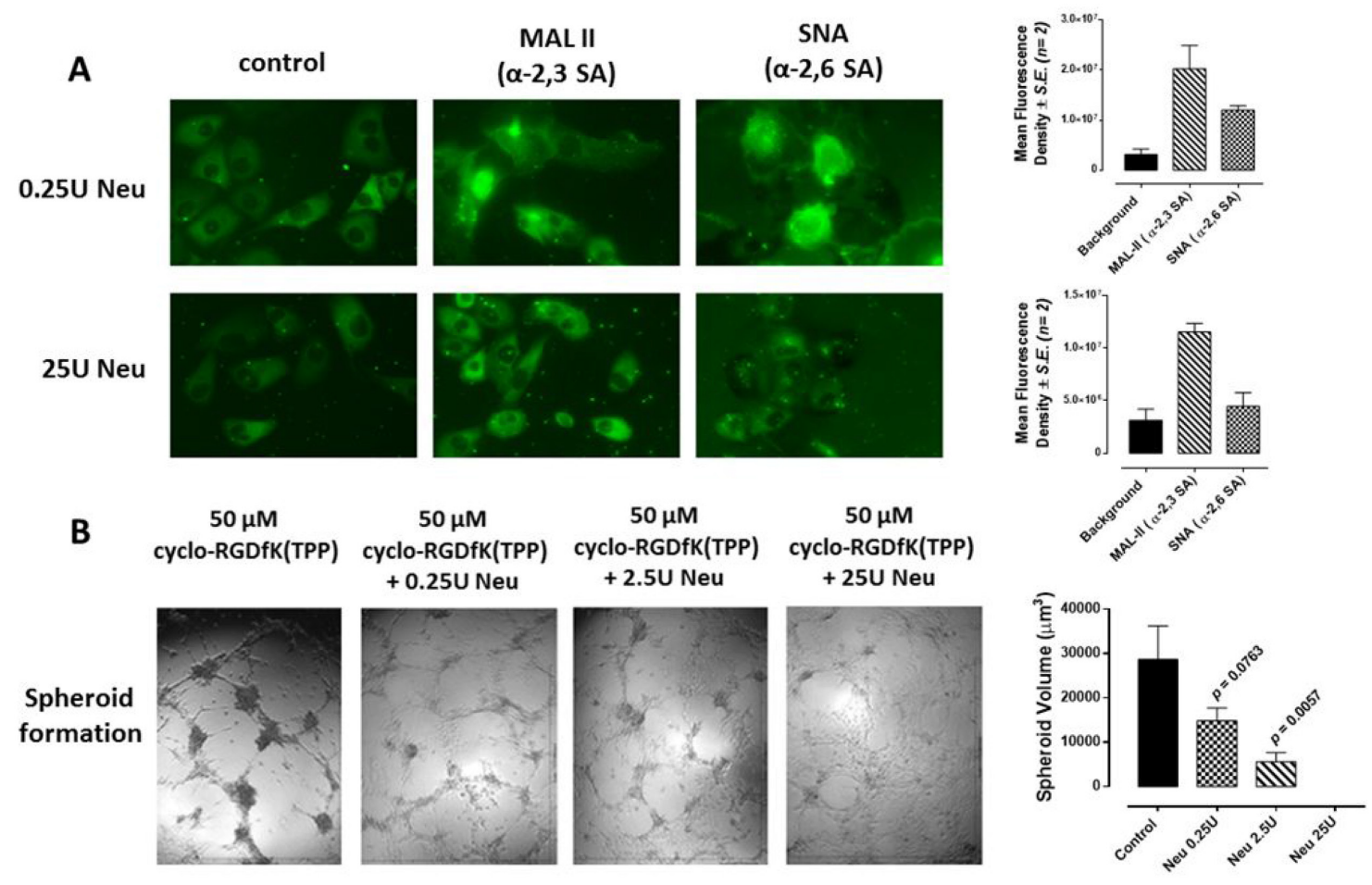

Figure 5: A. Fluorescent microscopy images of MCF-7 stained with biotinylated MAL-II and SNA followed with avidinfluorescein after $24 \mathrm{~h}$ of incubation with $25 \mathrm{U}$ or $0.25 \mathrm{U}$ of neuraminidase (Neu) (Vibrio cholerae, cleavage of $\alpha 2,6-\mathrm{SA}>$ $\boldsymbol{\alpha 2 , 3 - S A}>\boldsymbol{\alpha 2}, 8-S A)$. Background control has only the avidin-fluorescein. Stained cells were visualized by epifluorescence microscopy using a x20 objective. Quantitative analysis was done by assessing the density of cell staining corrected for background in each panel using Corel Photo Paint 8.0 software. Each bar in the graphs represents the mean corrected density of staining $\pm S$.E. (error bars) for all cells within the respective images. B. MCF-7 cells were treated with neuraminidase (Neu, Vibrio cholerae) at the indicated dosages together with $50 \mu \mathrm{M}$ cyclo-RGDfK(TPP) with 10,000 cells per well in 96-well plate for 4 days of incubation. Spheroid volume was measured using V $=(4 / 3) \pi$ $\mathrm{r}^{3}$ where $\mathrm{r}=$ average radius (microns) with inverted microscope and $4 \mathrm{x}$ objective. Spheroid is defined as a compact rounded spheroid with a distinct border of diameter $\geq 60 \mu \mathrm{m}$ containing cells indistinguishable from one another. Each bar in the graph represents mean spheroid volume \pm S.E. (error bars) for all spheroids within the representative images. Results were compared by a one-way ANOVA at $95 \%$ confidence using Fisher's LSD test. Data are a representation of one out of three independent experiments showing similar results. 
A $\begin{array}{cccc}50 \mu \mathrm{M} & 50 \mu \mathrm{M} & 50 \mu \mathrm{M} & 50 \mu \mathrm{M} \\ \text { cyclo-RGDfK(TPP) } & \text { cyclo-RGDfK(TPP) } & \text { cyclo-RGDfK(TPP) } & \text { cyclo-RGDfK(TPP) }\end{array}$ $+50 \mu \mathrm{g} / \mathrm{mL}$ MAL ॥ $+5 \mu \mathrm{g} / \mathrm{mL}$ MAL ॥ $+0.5 \mu \mathrm{g} / \mathrm{mL} \mathrm{MAL} \mathrm{II}$

MCF-7
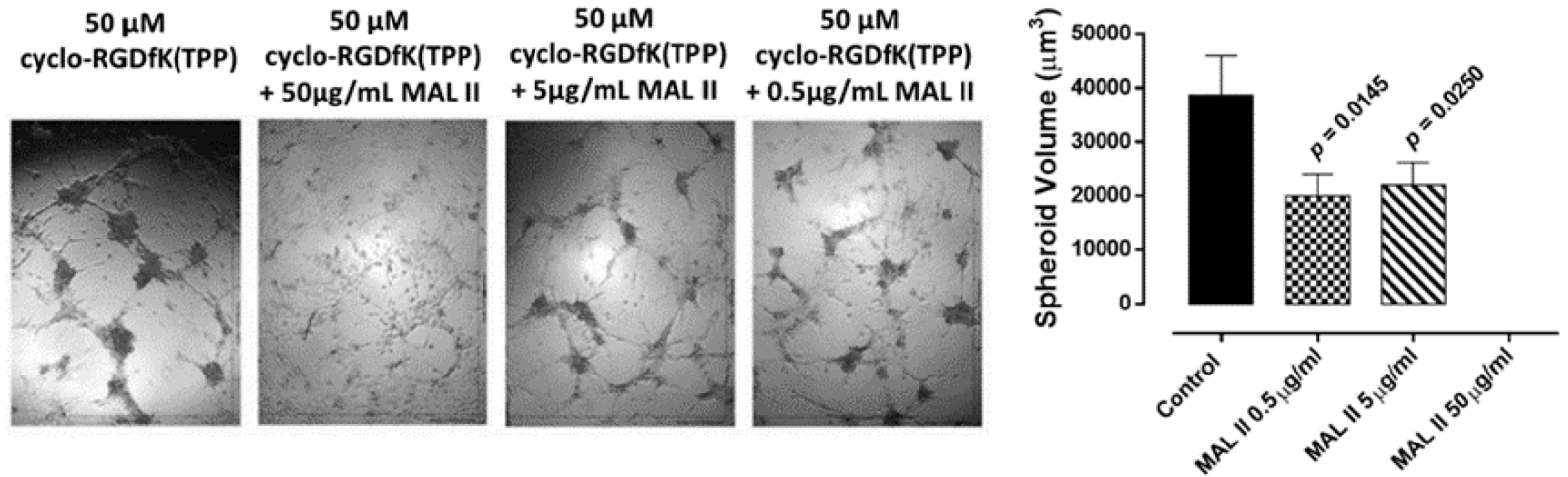

B
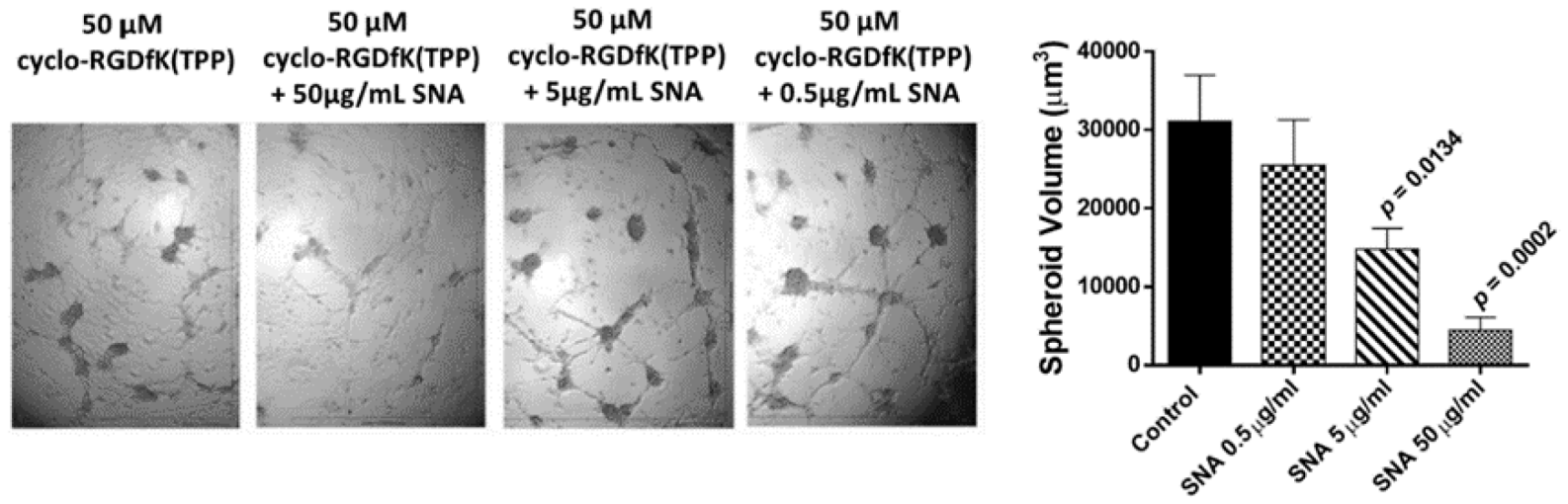

C
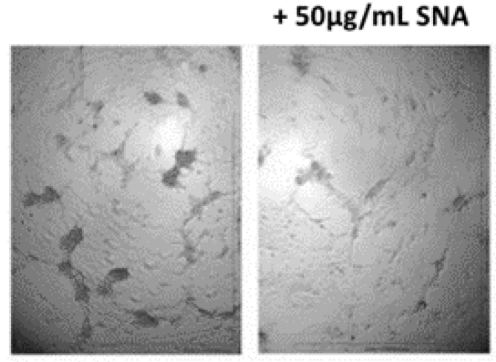

MCF-7
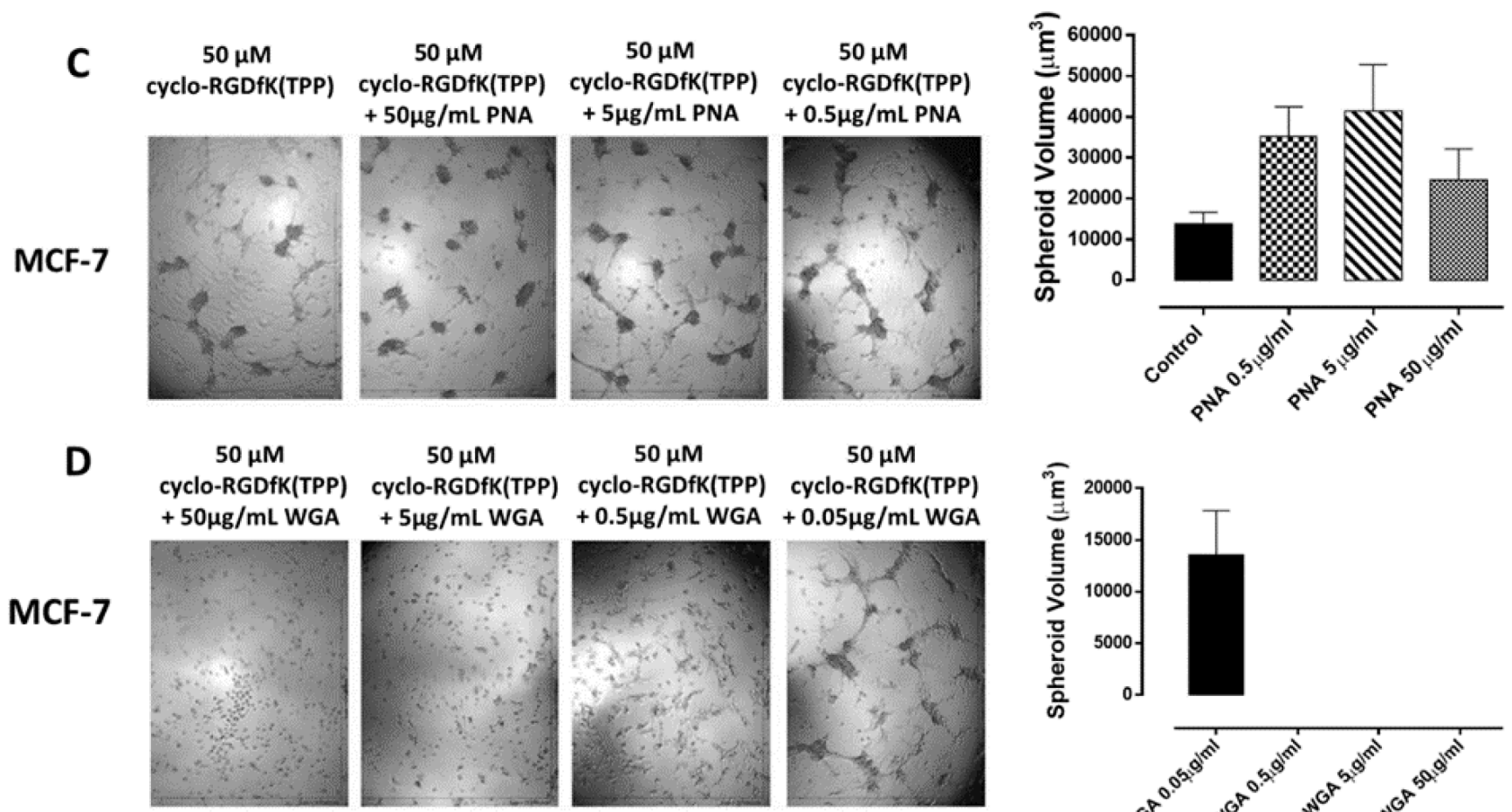

$50 \mu \mathrm{M}$
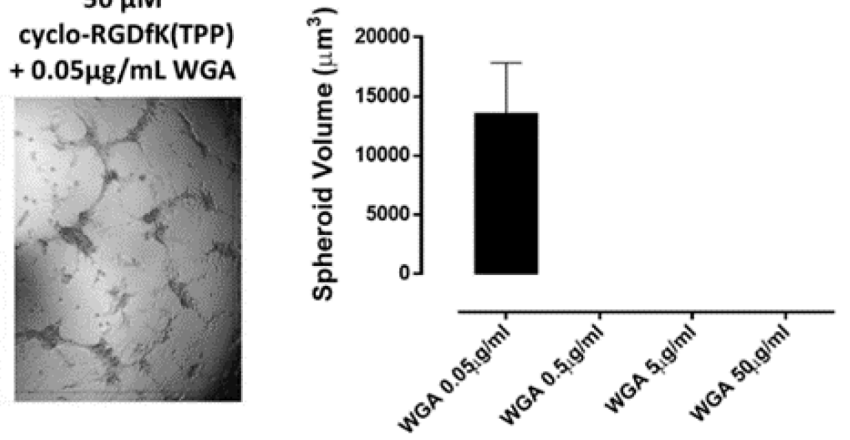

Figure 6: MCF-7 cells were treated with A. M. amurensis lectin MAL II ( $\alpha 2,3-\mathrm{SA})$, B. Sambucus nigra lectin SNA ( $\alpha 2,6-$ SA), C. peanut agglutinin PNA (specific for galactosyl $(\beta-1,3)$ N-acetylgalactosamine) or $\mathrm{D}$. wheat germ agglutinin WGA ( $\mathrm{N}$-acetylglucosamine residues) at the indicated dosages together with $50 \mu \mathrm{M}$ cyclo-RGDfK(TPP) and 10,000 cells per well in 96-well plate for 4 days of incubation. Spheroid volume was measured using $V=(4 / 3) \pi r^{3}$ where $r=$ average radius (microns) with inverted microscope and $4 \mathrm{x}$ objective. Each bar in the graph represents mean spheroid volume \pm S.E. (error bars) for all spheroids within the representative images. Results were compared by a one-way ANOVA at 95\% confidence using Fisher's LSD test. Data are a representation of one out of three independent experiments showing similar results. 
OP. For $\mathrm{OP} \geq 400 \mu \mathrm{g} / \mathrm{mL}$, the cell viability of monolayer PANC1 cells [44], MCF-7 and tamoxifen-resistant MCF-7 TMX cells [45] was significantly reduced after 3 days. For PANC1 and PANC1-GemR cells, $200 \mu \mathrm{g} / \mathrm{mL}$ OP and $50 \mu \mathrm{M}$ cyclo-RGDfK(TPP) for 5 days produced cell aggregates and compaction that were darker than those without OP, indicating improved cell compaction and tighter cell-cell contacts (Figure 6B). The effect of OP on spheroid formation might be explained by (a) OP increases the expression of E-cadherin [44], an important role in spheroid compaction of breast carcinoma [46], hepatoma [47] and hepatocytes [48, 49] and/or (b) inhibition of Neu4 sialidase [38].

\section{Sialylation of cell surface glycoproteins in xenograft tumors of PANC 1 and MDA-MB231 cancer cells in mouse models of human disease}

Levels of $\alpha 2,6-\mathrm{SA}$ and $\alpha 2,3-\mathrm{SA}$ expression were analyzed in tumor-derived sections of PANC1 and MDAMB231 xenografts growing in RAGxC $\gamma$ double mutant mice. Cohorts were dosed with $50 \mathrm{mg} / \mathrm{kg}$ oseltamivir phosphate (OP) for PANC1 tumors or $30 \mathrm{mg} / \mathrm{kg}$ OP for MDA-MB231 tumors, and were analyzed in comparison to their respective, untreated cohorts. Since OP affects $\alpha 2,3-\mathrm{SA}$ expression in PANC1 and MCF-7 cells, paraffinembedded necropsy tumor sections were investigated for differences in $\alpha 2,6-\mathrm{SA}$ and $\alpha 2,3-\mathrm{SA}$ expression levels. Using fluorescence histochemical staining, tumors from OPtreated cohort showed strong staining for $\alpha 2,3-\mathrm{SA}$ compared with the untreated cohort (Figure 8). Sections with no primary antibody added (background fluorescence control) demonstrated minimal non-specific staining. Our findings also show that avascular MCF-7 tumor spheroids express higher $\alpha 2,3-\mathrm{SA}$ over $\alpha 2,6-\mathrm{SA}$ (Figure 9). Collectively, these data implicate a novel role for cell-surface sialylation, in relation to both sialic acid content and linkage specificity, in the formation of multicellular tumor spheroids.

\section{DISCUSSION}

MCF-7 and PANC-1 cells, and their drug-resistant cancer cell lines (MCF-7 TMX, PANC1-GemR) express

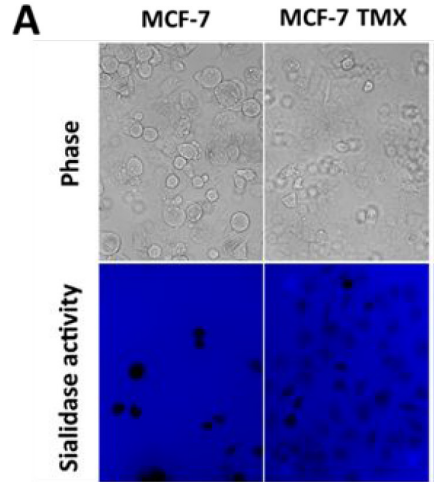

B

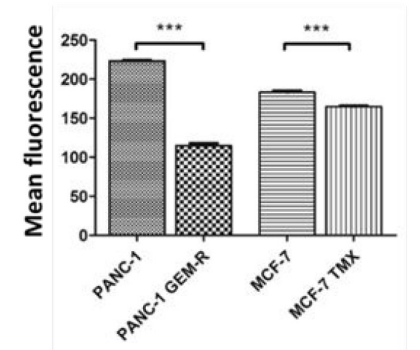

PANC1 PANC1 GemR

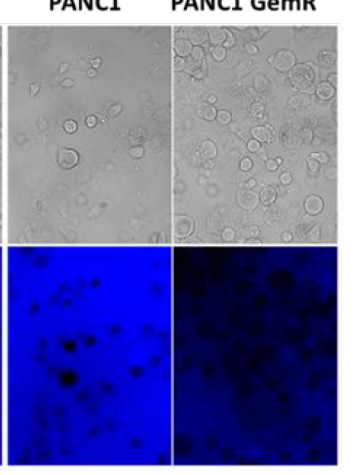

D

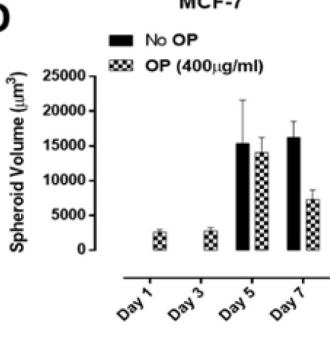

C
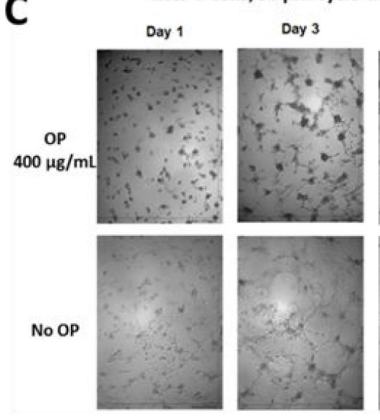

$\mathbf{E}$



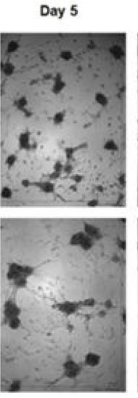
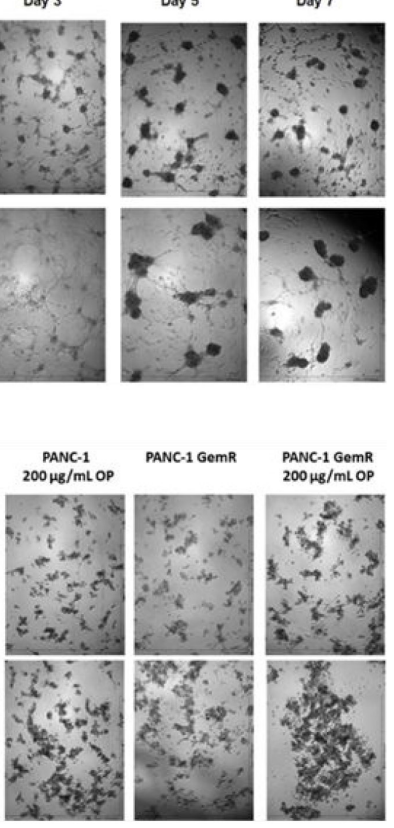

Figure 7: A. Sialidase activity in indicated live cells. Cells were allowed to adhere on 12 mm circular glass slides in media containing $10 \%$ fetal calf sera for $\mathbf{2 4} \mathbf{h}$. After removing medium, $0.318 \mathrm{mM} 4-\mathrm{MUNANA}$ (4-MU) substrate (2'-(4-methlyumbelliferyl)$\alpha-\mathrm{N}$-acetylneuraminic acid) in Tris-buffered saline ( $\mathrm{pH}$ 7.4) was added to live cells alone. The substrate was hydrolyzed by sialidase enzymes expressed on cell surface to give free 4-methylumbelliferone, which has a fluorescence emission at $450 \mathrm{~nm}$ (blue color) following excitation at $365 \mathrm{~nm}$. Fluorescent images were taken at 1-2 min after adding substrate using epi-fluorescent microscopy (10× objective). B. The mean fluorescence of 50 multi-point replicates was quantified using the Image J software. Results were compared by a one-way ANOVA at $95 \%$ confidence using t-test. Data are a representation of one out of three independent experiments showing similar results. C. MCF-7 spheroid formation in the presence of $50 \mu \mathrm{M}$ of cyclo-RGDfK(TPP) with $400 \mu \mathrm{g} / \mathrm{mL}$ OP or without (no inhibitor) with 10,000 cells per well in 96-well plate for 1-7 days of incubation. D. Spheroid volume was measured using V $=(4 / 3) \pi \mathrm{r}^{3}$ where $\mathrm{r}=$ average radius (microns) with inverted microscope and $4 \mathrm{x}$ objective. Each bar in the graph represents mean spheroid volume $\pm S . E$. (error bars) for all spheroids within the representative images. E. PANC1and PANC1-GemR cell aggregation and compaction in the presence of $25 \mu \mathrm{M}$ or 50 $\mu \mathrm{M}$ of cyclo-RGDfK(TPP) with or without $200 \mu \mathrm{g} / \mathrm{mL}$ OP, 5 days of incubation. 


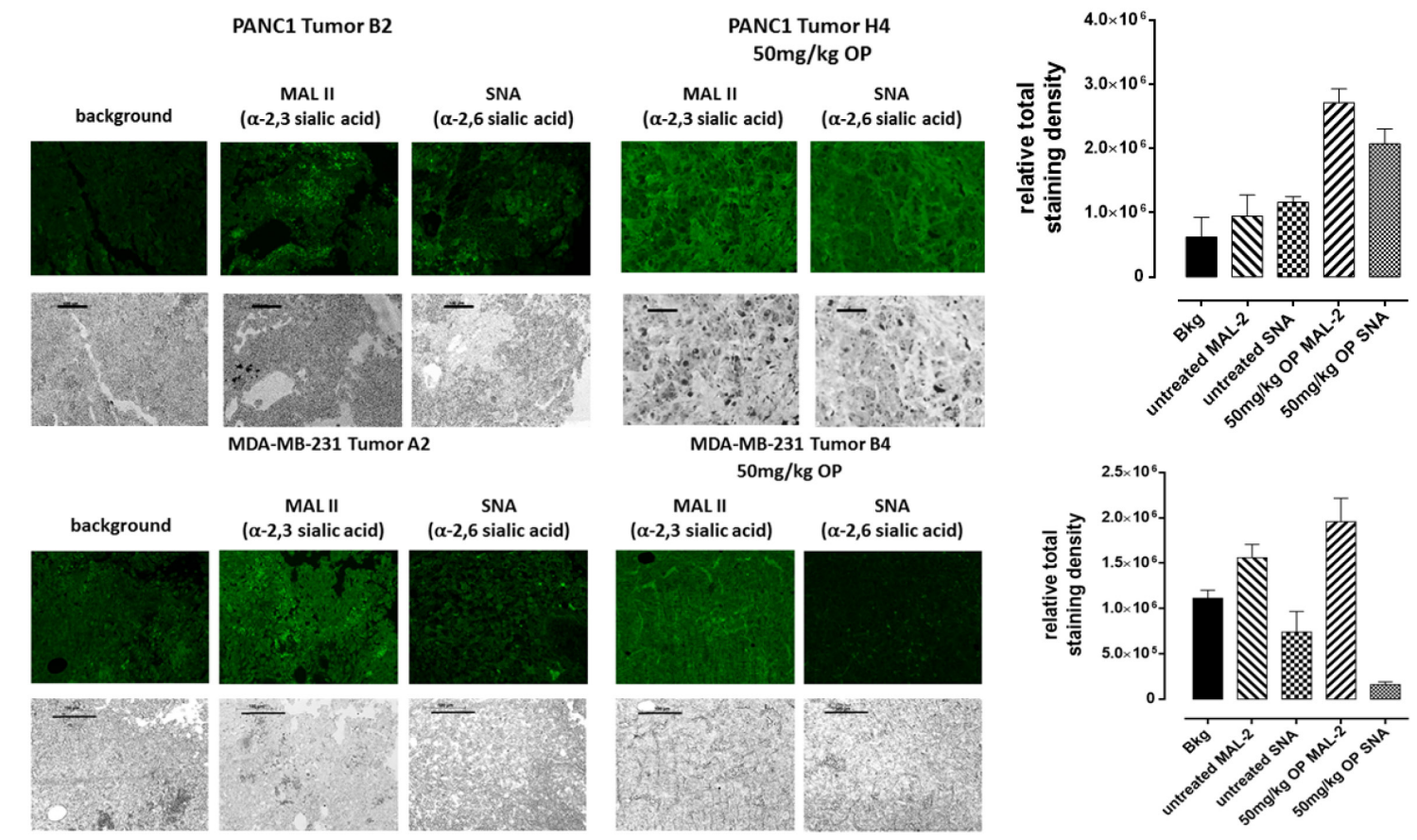

Figure 8: Fluorescence histochemical detection of $\alpha-2,3 \mathrm{SA}$ and $\alpha-2,6 \mathrm{SA}$ expressions in paraffin-embedded tumor tissues archived from xenograft tumors of PANC 1 and MDA-MB231 cells growing in RAG xC $\gamma$ double mutant mice. Mice were implanted with $1 \times 10^{6}$ PANC1 or MDA-MB231 cells cutaneously on the rear flank and OP treatment at indicated dosages began at 22-23 days post implantation when tumors reached 100-200 mm3. Paraffin-embedded tumor sections $(5 \mu \mathrm{m})$ on glass slides were processed for lectin histochemistry using biotinylated MAL II and SNA followed with avidin fluorescein and fluorescence mounting media. Background control sections (Bkg) were prepared without the biotinylated lectins. Tissue sections were visualized and photographed using a Zeiss Imager M2 fluorescence microscope at 200× magnification. Images are representative of at least five fields of view from two tumor sections.

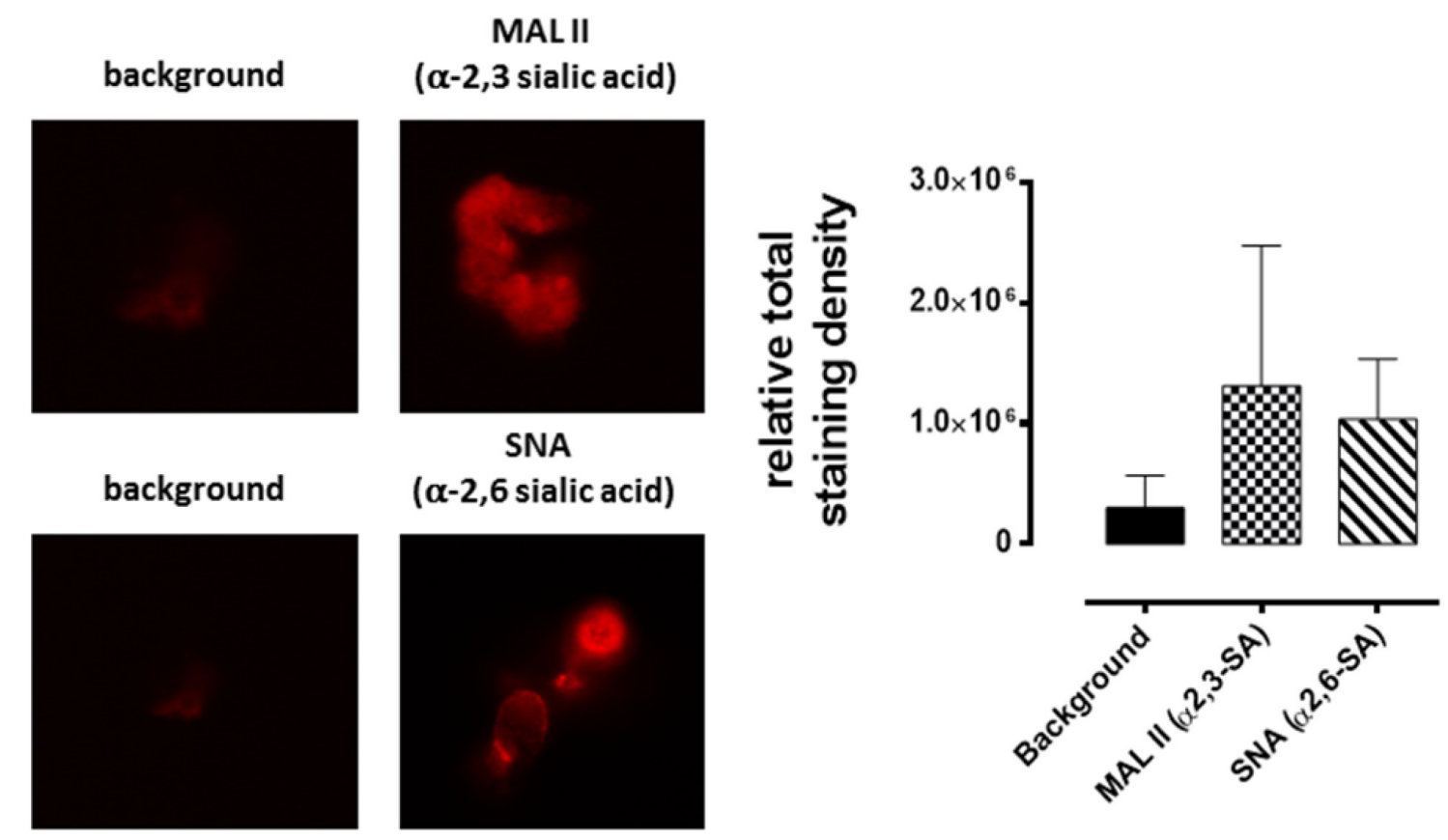

Figure 9: Fluorescence cytochemical detection of $\alpha-2,3 \mathrm{SA}$ and $\alpha-2,6 \mathrm{SA}$ expressions in MCF-7 spheroids. Spheroids on glass slides were processed for lectin histochemistry using biotinylated MAL II and SNA followed with streptavidin DyLight 594 and fluorescence mounting media. Background control sections (Bkg) were prepared without the biotinylated lectins. Spheroids were visualized and photographed using a Zeiss Imager M2 fluorescence microscope at 200× magnification. Images are representative of at least five fields of view. 
different SA content, which influenced their ability to form spheroids under cyclo-RGDfK(TPP)-induced self-assembly. Cancer cell aggregation and compaction correlates with the presence of $\alpha-2.3$ - and $\alpha-2,6$-sialic acid cell surface residues to form spheroids under cyclo-RGDfK(TPP)-induced self-assembly. Removal or blockage of SA inhibited cell aggregation for MCF7 and MCF-7 TMX cells under cyclo-RGDfK(TPP) peptide. Neuraminidase inhibitor oseltamivir phosphate enhanced cell aggregation and promoted compaction of cell aggregates.

Using the classical agarose-coated plates to form spheroids in a time-dependent manner, spheroid-forming MCF-7 vs MCF-7 TMX cells and PANC1 vs PANCGemR cells did not show any differences in spheroid cell formation (Supplemental Figure 1). In the classical platform of spheroid formation, including agarose-coated wells, hanging drop, and rotary culture, the resulting cell aggregation and compaction occur due to acting mechanical forces and/or surface properties which may prevent cell attachment to the cellular matrix in the culture well plate. To form spheroids, all of the cells are required to be in a $3 \mathrm{D}$ configuration. Raghavan et al. [1] have recently compared different methodologies to generate tumor spheroids in terms of morphology, cellular arrangement, and chemosensitivity. These methods include hanging drop array plates, liquid overlay on ultralow attachment plates, and liquid overlay on ultra-low attachment plates with rotating mixing (nutator plates). They found that the different methods of tumor spheroid generation resulted in varied cellular arrangement and chemosensitivity. For most currently available 3D classical methods for spheroid formation, these techniques are time consuming, lack reproducibility and mainly rely on microscopic observations, thus there is a need to standardize and develop rapid protocols for tumor spheroid formations [50].

Terao et al. [32] demonstrated that the gemcitabineresistant pancreatic cancer cells (PANC1-RG) contained a greater population of cells with stem cell-like properties, when compared to the parental PANC1 cells. Specifically, the stem cell-like phenotype was characterized by higher levels of both CD24 and CD44 in the PANC1-RG cells. The same group also found that PANC1-RG cells could form spheroids more effectively, and larger in size, than their PANC1 counterparts. It is noteworthy that a few studies using spheroid formation on chemoresistant cancer cells have been performed $[14,50]$. It is interesting to note from the report by Terao et al. [32] that sphere-forming cells and PANC1 stem-like cells expressed high levels of fucosylated glycans. Using AAL and AOL lectins in western blot analysis, it was found that spheroid-forming cells demonstrated increased binding to both lectins, when compared to the monolayer cells [32]. These findings may be partially explained by the branched N-glycans, including fucosylation sites, covalently conjugated to cell adhesion molecules. These glycans, linked to both cadherins and integrins, are known to play key structural and functional roles in cell-cell recognition and interaction [51].

Consistent with this premise, several other reports have shown that breast carcinoma cell lines [46], hepatoma [47] and hepatocytes [48, 49] are able to form spheroids dependent on E-cadherin. Iglesias et al. [46] analyzed the capability of 11 breast cancer cell lines to form mammospheres, and thus able to continually proliferate in a non-adherent state. Only MCF7, T47D, BT474, MDA-MB-436 and JIMT1 cells could be passaged and developed into mammospheres, while other cancer cells including SKBR3, MDA-MB-231, MDA-MB-468 and MDA-MB-435 could only form temporary aggregates, with dramatic reduction in cell viability upon a second passage.

The previously described report by Silvestri et. al [38] demonstrated that glioblastoma stem cells (GSC), isolated from patients and multiforme cell lines, are associated with an upregulation of Neu4 activity. The catalytic activity of Neu4 has been shown to trigger key events in glioblastoma stem cells, including (a) glycogen synthase kinase 3B (GSK3b) activation, (b) subsequent suppression of Sonic Hedgehog and Wnt/B-catenin signaling, (c) downregulation of stem cell-like gene expression and biomarkers (characterized by a significant decrease in NANOG, OCT-4, SOX-2, CD133, ganglioside GD3, and aberrant protein glycosylation patterns), and (d) a marked reduction in GSC viability. TQ-induced Neu4 activity can target plasma membrane-bound sialylated receptors such as TOLL like receptor 4 (TLR4) [42]. The proposed mechanism occurs through a cell-surface signaling axis consisting of MMP-9 and neuromedin B GPCR, which form complexes with TLR4 to generate a functional receptor. Collectively, the inhibition of Neu4 and/or Neu1 with OP is proposed to affect the sialylation of glycoproteins and glycolipids on the cell surface. This results in a glycome phenotypically similar to that of differentiated cells, and thus reducing the stem cell-like glycosylation phenotype.

The potential clinical implications of these studies suggest that selectively targeting Neu4 and Neu1 could modify the glycosylation state of cell surface proteins, thus reducing tumor growth and preventing metastatic disease. Preclinical data from our studies reveal significant and reproducible in vitro and in vivo results that OP therapy decreases EGF receptor over-activity and downstream signaling in cancer cells and in tumor lysates obtained from heterotopic xenografts of $\mathrm{MiaPaCa}-2$ pancreatic tumors growing in RAGxC $\gamma$ double mutant mice [37]. OP therapy also impeded tumor growth, blocks tumor neovascularization and metastases. Collectively, we propose here that Neul is a novel alternate candidate target using OP therapy in restraining the growth, metastases, tumor neovascularization as well as macrophage-mediated 
tumorigenesis of human cancers. Here, Neu1 forms a complex with a broad range of glycosylated growth factor receptors including extracellular and intracellular TOLLlike (TLR) sensing receptors, as reviewed by Haxho et al [22].

In conclusion, tumor spheroids have emerged and show promise as a model for investigating growth and development of tumors, cancer cell motility, and drug efficacy. The present report provides evidence for the important role of specific sialoglycan structures expressed on cancer cells to form avascular multicellular tumor spheroids and in vivo xenograft tumors. Future studies should build upon these findings and explore alternate and novel methods to target the cancer cell glycome and the unique sialylation patterns of the adhesion molecules involved in spheroid formation and tumor progression.

\section{MATERIALS AND METHODS}

\section{Reagents}

Maackia amurensis lectin II (MAL II) was purchased from Sigma. Sambucus nigra lectin (SNA), Peanut Agglutinin (PNA) and Wheat Germ Agglutinin (WGA) was bought from Vector Laboratories. ArgGly-Asp-D-Phe-Lys (cyclo-RGDfK) modified with 4-carboxy-butyl-triphenylphosphonium bromide (cycloRGDfK(TPP)) peptide was synthesized by Prof. Dr. S. Burov, Saint-Petersburg, Russia and further characterized by us [31].

Neuraminidase from Vibrio cholerae was obtained from GIBCO laboratories. Neuraminidase hydrolyzes terminal N- or O-acylneuraminic acids which are $\alpha 2,6-$, $\alpha 2,3-$, or $\alpha 2,8$-linked (rate: $\alpha 2,6>\alpha 2,3>\alpha 2,8$ ) to oligosaccharides, polysaccharides, mucopolysaccharides, glycoproteins, and glycolipids. One unit is the enzyme activity that hydrolyzes $1 \mu \mathrm{mol} \mathrm{N}$-acetyl-neuraminosylD-lactose within $1 \mathrm{~min}$ at $37^{\circ} \mathrm{C}$ under the following incubation conditions: $10 \mathrm{mM}$ N-acetyl-neuraminosyl-Dlactose, $50 \mathrm{mM}$ sodium acetate, $4 \mathrm{mM}$ calcium chloride, bovine serum albumin, $100 \mu \mathrm{g} / \mathrm{ml}, \mathrm{pH}$ 5.5. Specific activity of neuraminidase (Vibrio cholera) is $1 \mu \mathrm{mol}$ $\mathrm{N}$-acetylneuraminic acid per min is split off from human acid $\alpha 1$-glycoprotein (10 $\mathrm{mg} / \mathrm{ml}$ incubation mixture) by 1 U neuraminidase.

\section{Cell lines}

Human cell lines (breast adenocarcinoma MCF7 (ATCC $®$ HTB-22 ${ }^{\mathrm{TM}}$ )) and pancreatic carcinoma PANC1 (ATCC ${ }^{\circ}$ CRL-1469 ${ }^{\mathrm{TM}}$ ) were purchased from ATCC (Manassas, VA 20110 USA) collection. The cells were grown in $1 \times$ Dulbecco's Modified Eagle's Medium (DMEM; Gibco, Rockville, MD, USA) conditioned medium, supplemented with $10 \%$ fetal calf serum (FCS; HyClone, Logan, UT, USA), and $5 \mu \mathrm{g} / \mathrm{mL}^{\text {plasmocin }}{ }^{\mathrm{TM}}$
(InvivoGen, San Diego, CA, USA) in a $5 \% \mathrm{CO}_{2}$ incubator at $37^{\circ} \mathrm{C}$. At $\sim 80 \%$ confluence, the cells were passaged at least five times before use in the experiments. Tamoxifenresistant MCF-7 TMX and gemcitabine-resistant PANC1GemR cells were cultured in media containing $10 \mu \mathrm{M}$ tamoxifen and $0.01 \mu \mathrm{M}$ gemcitabine, respectively, for over one year, authenticated in Szewczuk's lab.

\section{Fluorescent lectin cytochemistry for sialic acid (SA) expression}

Cells were seeded and grown overnight on $12 \mathrm{~mm}$ circular glass slides in conditioned medium in a sterile 24-well tissue culture plate for 24 hours. Cells were washed with PBS and fixed with 4\% paraformaldehyde (PFA) for $20 \mathrm{~min}$ or cold methanol (20 min). Following fixation, cells were washed with $1 \mathrm{x}$ phosphate-buffered saline $\mathrm{pH} 7.4$ (PBS) and stained with indicated lectins. SNA (biotinylated elderberry bark lectin, B-1305, Vector Laboratories) and MAL II (biotinylated Maackia amurensis lectin II, B-1265, Vector Laboratories) at concentrations of $10 \mu \mathrm{g} / \mathrm{mL}$ in PBS were incubated on slides for $1 \mathrm{hr}$ at room temperature. Stained slides were then washed twice with PBS and incubated $1 \mathrm{hr}$ with avidin-fluorescein $(10 \mu \mathrm{g} / \mathrm{mL})$. Cells without biotinylated lectins were used as controls. After three washings with PBS, slides were mounted in cell mounting media and analyzed with Carl Zeiss Imager 2 fluorescence microscope.

\section{Sialidase assay}

Cells were grown overnight on $12 \mathrm{~mm}$ circular glass slides in conditioned medium in a sterile 24-well tissue plate. Before the experiment, the cells were incubated in starvation (serum-free) medium for two hours to reach the baseline level of sialidase activity in each cell line. The media was removed and $0.318 \mathrm{mM}$ 4-MUNANA (2'-(4-methylumbelliferyl)- $\alpha-\mathrm{D}-\mathrm{N}$-acetylneuraminic acid; Biosynth Intl.) substrate in Tris-buffered saline (TBS, pH 7.4) was added to each well. The substrate was hydrolyzed by sialidase to give free 4-methylumbelliferone, which has a fluorescence emission at $450 \mathrm{~nm}$ (blue color) following an excitation at $365 \mathrm{~nm}$. Fluorescent images were taken after 1-2 min using epi-fluorescent microscopy (40× objective). The mean fluorescence surrounding the cells was quantified using the Image J program.

\section{WST-1 assay}

The WST-1 assay, a measure of cell viability based on the reduction of a tetrazolium compound to a soluble derivative [33], was used. The absorbance recorded at 420 $\mathrm{nm}$ is directly proportional to the number of living cells in culture. At 80-90\% confluence, floating spheroids and attached cells were added to 96-well microwell plates at a 
density of 5,000 cells/well and incubated overnight. The cells were left untreated as controls for 4 days. Absorbance readings were taken by adding WST-1 (Roche Diagnostics Division de Hoffman La Roche Limitée, Laval-desRapides, QC, Canada) as a cell proliferation reagent to each well (10\% WST-1 in Dulbecco's Modified Eagle's Medium), followed by incubation at $37^{\circ} \mathrm{C}$ for 2 hours before reading at the indicated time point. Cell viability was presented as a percentage of control, and illustrated as a bar graph using GraphPad Prism software (GraphPad Software, La Jolla, CA, USA). The following formula was used to determine cell viability as a percent of control for each peptide concentration, where day 0 is when peptide was added:

[(Absorbance of cells in given concentration of peptide)-(Media absorbance) $]$ /

$[($ Absorbance of cells alone on day 0$)-($ Media absorbance) $] \times 100$

\section{Flow cytometry of cell surface SA in live cells}

Flow cytometry analysis of biotinylated MAL II or biotinylated SNA was conducted through staining of live cell surfaces. Live cells were stained with biotinylated lectins after incubation on ice for $1 \mathrm{hr}$ and followed with DyLight 488 conjugated strept-avidin for additional 30 min on ice. They were then fixed. Control cells were stained with DyLight488 conjugated strept-avidin for 30 min on ice. Cells were analyzed by Beckman Coulter Cytomics FC500 flow cytometry and CxP software (Beckman Coulter) in the Queen's University Biomedical Imaging Center (QUBIC), Faculty of Health Sciences. Overlay histograms are displayed. Control unstained cells are depicted as gray-filled histogram. DyLight 488 conjugated strept-avidin treated cells are represented by the black-dashed unfilled histogram. Biotinylated SNA stained cells plus DyLight 488 conjugated strept-avidin are depicted by unfilled histogram with the dotted black line. Biotinylated MAL II stained cells plus DyLight 488 conjugated strept-avidin are depicted by unfilled histogram with the black line. The median fluorescence for each histogram is indicated for 500,000 acquired cells ( $100 \%$ gated). The data are a representation of one out of two experiments showing similar results.

\section{Agarose-based classical technique of spheroids formation}

Tumor spheroid formation on agarose-coated plates was performed as previously described [52]. Briefly, 1.5\% wt of agarose in 1xDMEM was heated on water bath for $15 \min .50 \mu \mathrm{L}$ of agarose gel was added to each well of a flat-bottom 96-well plate under sterile conditions. Plates with agarose were cooled down to room temperature for 15 minutes. Cells were seeded on agarose-coated plates (5,000-10,000 cells/well, $100 \mu \mathrm{L}$ of media in each well) and incubated at $37^{\circ} \mathrm{C}$ for $1-7$ days.

\section{RGD peptides-based technique of spheroid formation}

Spheroid formation was carried out as previously described by us [31]. Briefly, cells were seeded in a flat-bottom 96-well plate $(5,000-10,000$ cells/well, $100 \mu \mathrm{L} /$ well) and incubated at $37^{\circ} \mathrm{C}$ for $2-3 \mathrm{~h}$ until the cells attached to the plate bottom. The medium was replaced with $100 \mu \mathrm{L}$ of $1 \mathrm{xDMEM}$ containing a cycloRGDfK(TPP) peptide $(25-50 \mu \mathrm{M})$. The plate was incubated at $37^{\circ} \mathrm{C}$ for additional 1-7 days.

\section{Measurement of spheroid volume}

Spheroid volume was determined from images obtained with an inverted microscope using $4 \mathrm{x}$ or $10 \mathrm{x}$ objectives and defined as a compact rounded spheroid with a distinct border of diameter $\geq 60 \mu \mathrm{m}$ containing cells indistinguishable from one another. The following formulae were used to determine spheroid volume:

10x objective images: $V=(4 / 3) \pi r^{3}$ where $r=$ average radius (microns)

4x objective images: $\mathrm{V}=(2.5)(4 / 3) \pi \mathrm{r}^{3}$ where $\mathrm{r}=$ average radius (microns)

For the 4x objective images, the formula includes 2.5 to normalize values to the $10 \mathrm{x}$ objective images.

\section{Lectin histochemistry staining of archived xenograft tumors}

Lectin histochemistry staining was used to determine the presence of the characteristic $\alpha-2,3-\mathrm{SA}$ and $\alpha-2,6-\mathrm{SA}$ expression in human pancreatic PANC1 and triple negative breast MDA-MB231 tumors removed at necropsy from tumor-bearing $\mathrm{RAG} 2 \mathrm{xC} \gamma$ double mutant mice, which had received various treatments (oseltamivir phosphate $50 \mathrm{mg} / \mathrm{kg}$ for PANC1 and $30 \mathrm{mg} / \mathrm{kg}$ for MDA-MB231 or untreated). Archived processed tumors embedded in paraffin blocks were obtained from previous experiments. An immunodeficient mouse model with a double mutation in RAG2 and $\mathrm{C} \gamma$ was used as a xenograft mouse model of human pancreatic and breast cancers, as previously reported by our group [45]. The $\mathrm{RAG} 2 \mathrm{xC} \gamma$ double mutant mice were implanted cutaneously with $1 \times 10^{6}$ cells and OP treatment was started 10 days postimplantation for MDA-MB231 [45] and 16 days for PANC1. Treatment was continued until the mice either died or were euthanized at the end of the experiment. Tumor sections $(5 \mu \mathrm{m})$ were deparaffinized, heated for 10 minutes in citrate buffer for antigen retrieval, rinsed three times in phosphate-buffered saline, and blocked in $1 \%$ bovine serum albumin (Fisher Scientific Company) for 2 hours. Sections were then incubated with biotinylated MAL II or biotinylated SNA overnight, followed by incubation with avidin fluorescein for two hours. Coverslips were added using DAKO fluorescent mounting medium. Background control sections were also prepared 
in the same way as above, without biotinylated lectins. Tissue sections were visualized and photographed using a Zeiss Image M2 microscope at 200× magnification.

\section{ACKNOWLEDGMENTS}

S. Haq is the recipient of Queen's Graduate Award (QGA) and the 2016 Ontario Graduate Scholarship (OGS). F. Haxho was the recipient of Queen's Graduate Award (QGA), the Graduate Entrance Tuition Award (GETA), the Natural Sciences and Engineering Research Council of Canada (NSERC) Alexander Graham Bell Canada Graduate Scholarship-Master's (CGS M) and now the Vanier Canada Graduate Scholarship. V. Samuel is the recipient of the Queen's University Principal's Scholarship and the Board of Governor's Award.

Authors acknowledge Matt Gordon, coordinator of the Queen's University Biomedical Imaging Center (QUBIC), Faculty of Health Sciences for his expertise in performing the flow cytometry.

\section{CONFLICTS OF INTEREST}

The authors declare no competing financial or conflicts of interest.

\section{GRANT SUPPORT}

This work was supported in part by grants to M.R. Szewczuk and R. J. Neufeld from NSERC and private sector cancer funding from the Josefowitz Family to M.R. Szewczuk.

\section{REFERENCES}

1. Raghavan S, Mehta P, Horst EN, Ward MR, Rowley KR, Mehta G. Comparative analysis of tumor spheroid generation techniques for differential in vitro drug toxicity. Oncotarget. 2016. doi: 10.18632/oncotarget.7659.

2. Friedrich J, Seidel C, Ebner R, Kunz-Schughart LA. Spheroid-based drug screen: considerations and practical approach. Nat Protoc. 2009; 4.

3. Hirschhaeuser F, Menne H, Dittfeld C, West J, MuellerKlieser W, Kunz-Schughart LA. Multicellular tumor spheroids: an underestimated tool is catching up again. J Biotechnol. 2010; 148 .

4. Haycock JW. 3D cell culture: a review of current approaches and techniques. Methods Mol Biol. 2011; 695.

5. Li Q, Chen C, Kapadia A, Zhou Q, Harper MK, Schaack J, Labarbera DV. 3D Models of Epithelial-Mesenchymal Transition in Breast Cancer Metastasis: High-Throughput Screening Assay Development, Validation, and Pilot Screen. Journal of Biomolecular Screening. 2011; 16:141-154.
6. Lin R-Z, Chang H-Y. Recent advances in three-dimensional multicellular spheroid culture for biomedical research. Biotechnol J. 2008; 3:1172-1184.

7. Horning JL, Sahoo SK, Vijayaraghavalu S, Dimitrijevic S, Vasir JK, Jain TK, Panda AK, Labhasetwar V. 3-D Tumor Model for In Vitro Evaluation of Anticancer Drugs. Mol Pharmaceutics. 2008; 5:849-862.

8. LaBarbera DV, Reid BG, Yoo BH. The multicellular tumor spheroid model for high-throughput cancer drug discovery. Expert Opinion on Drug Discovery. 2012; 7:819-830.

9. Mehta G, Hsiao AY, Ingram M, Luker GD, Takayama S. Opportunities and challenges for use of tumor spheroids as models to test drug delivery and efficacy. Journal of Controlled Release. 2012; 164:192-204.

10. Kunjithapatham R, Karthikeyan S, Geschwind J-F, Kieserman E, Lin M, Fu D-X, Ganapathy-Kanniappan S. Reversal of Anchorage-Independent Multicellular Spheroid into a Monolayer Mimics a Metastatic Model. Sci Rep. 2014; 4:6816.

11. Correia AL, Bissell MJ. The tumor microenvironment is a dominant force in multidrug resistance. Drug Resistance Updates. 2012; 15:39-49.

12. Burleson KM, Casey RC, Skubitz KM, Pambuccian SE, Oegema TR, Jr., Skubitz AP. Ovarian carcinoma ascites spheroids adhere to extracellular matrix components and mesothelial cell monolayers. Gynecologic oncology. 2004; 93:170-181.

13. Lin R-Z, Chang H-Y. Recent advances in three-dimensional multicellular spheroid culture for biomedical research. Biotechnology Journal. 2008; 3:1172-1184.

14. Vinci M, Box C, Eccles SA. Three-Dimensional (3D) Tumor Spheroid Invasion Assay. 2015; e52686.

15. Pietsch J, Sickmann A, Weber G, Bauer J, Egli M, Wildgruber R, Infanger M, Grimm D. A proteomic approach to analysing spheroid formation of two human thyroid cell lines cultured on a random positioning machine. Proteomics. 2011; 11:2095-2104.

16. Kopp S, Slumstrup L, Corydon TJ, Sahana J, Aleshcheva G, Islam T, Magnusson NE, Wehland M, Bauer J, Infanger $\mathrm{M}$, Grimm D. Identifications of novel mechanisms in breast cancer cells involving duct-like multicellular spheroid formation after exposure to the Random Positioning Machine. Scientific Reports. 2016; 6:26887.

17. Dvorak HF, Weaver VM, Tlsty TD, Bergers G. Tumor microenvironment and progression. Journal of Surgical Oncology. 2011; 103:468-474.

18. Weaver VM, Petersen OW, Wang F, Larabell CA, Briand P, Damsky C, Bissell MJ. Reversion of the malignant phenotype of human breast cells in three-dimensional culture and in vivo by integrin blocking antibodies. J Cell Biol. 1997; 137.

19. Desgrosellier JS, Cheresh DA. Integrins in cancer: biological implications and therapeutic opportunities. Nature Reviews Cancer. 2010; 10:9-22. 
20. Desgrosellier JS, Cheresh DA. Integrins in cancer: biological implications and therapeutic opportunities. Nat Rev Cancer. 2010; 10:9-22.

21. Park JJ, Lee M. Increasing the alpha 2, 6 sialylation of glycoproteins may contribute to metastatic spread and therapeutic resistance in colorectal cancer. Gut Liver. 2013; 7:629-641.

22. Haxho F, Neufeld RJ, Szewczuk MR. Neuraminidase-1: A novel therapeutic target in multistage tumorigenesis. Oncotarget. 2016; 7:40860-40881. doi: 10.18632/ oncotarget.8396.

23. Sawada M, Moriya S, Saito S, Shineha R, Satomi S, Yamori T, Tsuruo T, Kannagi R, Miyagi T. Reduced sialidase expression in highly metastatic variants of mouse colon adenocarcinoma 26 and retardation of their metastatic ability by sialidase overexpression. Int J Cancer. 2002; 97:180-185.

24. Dennis J. Glycoprotein glycosylation and cancer progression. Biochimica et Biophysica Acta (BBA) General Subjects. 1999; 1473:21-34.

25. Dennis JW, Laferte S. Tumor cell surface carbohydrate and the metastatic phenotype. Cancer Metastasis Rev. 1987; 5:185-204.

26. Dennis JW, Laferte S, Waghorne C, Breitman ML, Kerbel RS. Beta 1-6 branching of Asn-linked oligosaccharides is directly associated with metastasis. Science. 1987; 236:582-585.

27. Hakomori S. Tumor-associated carbohydrate antigens defining tumor malignancy: basis for development of anticancer vaccines. Adv Exp Med Biol. 2001; 491:369-402.

28. Hakomori S. Glycosylation defining cancer malignancy: New wine in an old bottle. Proceedings of the National Academy of Sciences. 2002; 99:10231-10233.

29. Handa K, Hakomori SI. Carbohydrate to carbohydrate interaction in development process and cancer progression. Glycoconj J. 2012; 29:627-637.

30. Pochec E, Bubka M, Rydlewska M, Janik M, Pokrywka M, Litynska A. Aberrant glycosylation of alphavbeta3 integrin is associated with melanoma progression. Anticancer Res. 2015; 35:2093-2103.

31. Akasov R, Zaytseva-Zotova D, Burov S, Leko M, Dontenwill M, Chiper M, Vandamme T, Markvicheva E. Formation of multicellular tumor spheroids induced by cyclic RGD-peptides and use for anticancer drug testing in vitro. International journal of pharmaceutics. 2016; 506:148-157.

32. Terao N, Takamatsu S, Minehira T, Sobajima T, Nakayama $\mathrm{K}$, Kamada Y, Miyoshi E. Fucosylation is a common glycosylation type in pancreatic cancer stem cell-like phenotypes. World J Gastroenterol. 2015; 21:3876-3887.

33. Tan AS, Berridge MV. Superoxide produced by activated neutrophils efficiently reduces the tetrazolium salt, WST-1 to produce a soluble formazan: a simple colorimetric assay for measuring respiratory burst activation and for screening anti-inflammatory agents. J Immunol Methods. 2000; 238:59-68.

34. Cui H, Lin Y, Yue L, Zhao X, Liu J. Differential expression of the alpha2,3-sialic acid residues in breast cancer is associated with metastatic potential. Oncol Rep. 2011; 25:1365-1371.

35. Deman JJ, Van Larebeke NA, Bruyneel EA, Bracke ME, Vermeulen SJ, Vennekens KM, Mareel MM. Removal of sialic acid from the surface of human MCF-7 mammary cancer cells abolishes E-cadherin-dependent cell-cell adhesion in an aggregation assay. In Vitro Cell Dev Biol Anim. 1995; 31:633-639.

36. Valentiner U, Fabian S, Schumacher U, Leathem AJ. The influence of dietary lectins on the cell proliferation of human breast cancer cell lines in vitro. Anticancer Res. 2003; 23:1197-1206.

37. Gilmour AM, Abdulkhalek S, Cheng TSW, Alghamdi F, Jayanth P, O'Shea LK, Geen O, Arvizu LA, Szewczuk MR. A novel epidermal growth factor receptor-signaling platform and its targeted translation in pancreatic cancer. Cellular Signalling. 2013; 25:2587-2603.

38. Silvestri I, Testa F, Zappasodi R, Cairo CW, Zhang Y, Lupo B, Galli R, Di Nicola M, Venerando B, Tringali C. Sialidase NEU4 is involved in glioblastoma stem cell survival. Cell Death Dis. 2014; 5:e1381.

39. Amith SR, Jayanth P, Finlay T, Franchuk S, Gilmour A, Abdulkhalek S, Szewczuk MR. Detection of Neu1 sialidase activity in regulating Toll-like receptor activation. Journal of visualized experiments: JoVE. 2010.

40. Woronowicz A, Amith SR, De Vusser K, Laroy W, Contreras R, Basta S, Szewczuk MR. Dependence of neurotrophic factor activation of Trk tyrosine kinase receptors on cellular sialidase. Glycobiology. 2007; 17:10-24.

41. Amith SR, Jayanth P, Franchuk S, Siddiqui S, Seyrantepe V, Gee K, Basta S, Beyaert R, Pshezhetsky AV, Szewczuk MR. Dependence of pathogen molecule-induced toll-like receptor activation and cell function on Neul sialidase. Glycoconjugate Journal. 2009; 26:1197-1212.

42. Finlay TM, Abdulkhalek S, Gilmour A, Guzzo C, Jayanth P, Amith SR, Gee K, Beyaert R, Szewczuk MR. Thymoquinone-induced Neu4 sialidase activates NFKB in macrophage cells and pro-inflammatory cytokines in vivo. Glycoconjugate Journal. 2010; 27:583-600.

43. Finlay TM, Jayanth P, Amith SR, Gilmour A, Guzzo C, Gee K, Beyaert R, Szewczuk MR. Thymoquinone from nutraceutical black cumin oil activates Neu4 sialidase in live macrophage, dendritic, and normal and type I sialidosis human fibroblast cells via GPCR Galphai proteins and matrix metalloproteinase-9. Glycoconjugate Journal. 2010; 27:329-348.

44. O'Shea LK, Abdulkhalek S, Allison S, Neufeld RJ, Szewczuk MR. Therapeutic targeting of Neul sialidase with oseltamivir phosphate (Tamiflu(R)) disables cancer 
cell survival in human pancreatic cancer with acquired chemoresistance. OncoTargets and therapy. 2014; 7:117-134.

45. Haxho F, Allison S, Alghamdi F, Brodhagen L, Kuta VE, Abdulkhalek S, Neufeld RJ, Szewczuk MR. Oseltamivir phosphate monotherapy ablates tumor neovascularization, growth, and metastasis in mouse model of human triplenegative breast adenocarcinoma. Breast Cancer: Targets and Therapy. 2014; 6:191-203.

46. Manuel Iglesias J, Beloqui I, Garcia-Garcia F, Leis O, Vazquez-Martin A, Eguiara A, Cufi S, Pavon A, Menendez JA, Dopazo J, Martin AG. Mammosphere formation in breast carcinoma cell lines depends upon expression of E-cadherin. PLoS One. 2013; 8:e77281.

47. Lin RZ, Chou LF, Chien CC, Chang HY. Dynamic analysis of hepatoma spheroid formation: roles of E-cadherin and beta1-integrin. Cell Tissue Res. 2006; 324:411-422.

48. Takei R, Suzuki D, Hoshiba T, Nagaoka M, Seo SJ, Cho CS, Akaike T. Role of E-cadherin molecules in spheroid formation of hepatocytes adhered on galactose-carrying polymer as an artificial asialoglycoprotein model. Biotechnology letters. 2005; 27:1149-1156.

49. Luebke-Wheeler JL, Nedredal G, Yee L, Amiot BP, Nyberg SL. E-Cadherin Protects Primary Hepatocyte Spheroids From Cell Death by a Caspase-Independent Mechanism. Cell transplantation. 2009; 18:1281-1287.

50. Vinci M, Gowan S, Boxall F, Patterson L, Zimmermann M, Court W, Lomas C, Mendiola M, Hardisson D, Eccles SA. Advances in establishment and analysis of threedimensional tumor spheroid-based functional assays for target validation and drug evaluation. BMC Biology. 2012; 10:1-21.

51. Zhao Y, Sato Y, Isaji T, Fukuda T, Matsumoto A, Miyoshi E, Gu J, Taniguchi N. Branched N-glycans regulate the biological functions of integrins and cadherins. FEBS J. 2008; 275:1939-1948.

52. Friedrich J, Seidel C, Ebner R, Kunz-Schughart LA. Spheroid-based drug screen: considerations and practical approach. Nat Protoc. 2009; 4:309-324. 